\title{
Unilateral Pleomorphic Lipoma of the Eyebrow
}

\author{
Joey Hamilton ${ }^{a}$ Jennifer Tan ${ }^{b}$ Hardeep Singh Mudhar \\ Departments of ${ }^{a}$ Histopathology and ${ }^{b}$ Ophthalmology, and ${ }^{c}$ National Specialist Ophthalmic Pathology Service \\ (NSOPS), Department of Histopathology, Royal Hallamshire Hospital, Sheffield, UK
}

\section{Key Words}

Pleomorphic lipoma · Eyebrow · Subcutis mass

\begin{abstract}
Aim: Epithelial and soft tissue tumours of the eyebrow skin and subcutis are rare occurrences. We describe an unusual eyebrow subcutis mass in a 65-year-old female. Methods: A 65-year-old female presented with an 8- to 9-month history of a painless swelling over the right eyebrow that was sausage-shaped. The clinical differential diagnosis included neurofibroma/schwannoma, cyst, prolapsed fat or metastasis. The lesion was excised. Results: The histology revealed a lesion composed of rope-like collagen, some spindle cells, mature adipocytes and hyperchromatic multi-nucleate floret cells. The spindle and multi-nucleate floret cells showed immunohistochemical positivity for CD34. The features were of a primary pleomorphic lipoma. Conclusions: This is the first reported case of a pleomorphic lipoma of the eyebrow subcutis. We discuss the clinical and histological differential diagnosis, especially related to histological conditions with which pleomorphic lipoma can be confused, such as welldifferentiated liposarcoma.

(c) 2015 S. Karger AG, Basel
\end{abstract}

\section{Introduction}

Compared to the eyelid and orbit region, there are very few tumours reported in the ophthalmic pathology literature that arise from the eyebrow skin and subcutis/soft tissue. The commonest benign tumour of the eyebrow skin is pilomatrixoma [1] in the paediatric age group, followed by dermoid cysts [2]. Soft tissue lesions are even rarer, and case reports/few series for the following lesions have been documented: fibrous histiocytoma [3], osteoma cutis [4], cellular neurothekeoma [5], dermatofibrosarcoma protuberans [6], rhabdomyoma [7], neurofibroma [8], nodular fasciitis [9] and conventional lipoma [10]. We report the clinical and histopathological features of an eyebrow soft tissue mass in a 65-year-old female, discuss the clinical and histopathological differential diagnoses and survey the literature of eyebrow tumours affecting the subcutis.

\section{Case Report}

A 65-year-old female presented with an 8-to 9-month history of a slowly growing right eyebrow mass. She experienced occasional aches, but no redness or inflammation was noted. The visual acuity in the right eye was $6 / 6+2$, and in the left eye it was $6 / 6-1$. There was a non-tender, soft, non-tethered, mobile mass

\section{KARGER}

E-Mail karger@karger.com

www.karger.com/oop
(C) 2015 S. Karger AG, Basel

2296-4681/15/0021-0020\$39.50/0
Dr. Hardeep Singh Mudhar

National Specialist Ophthalmic Pathology Service (NSOPS),

Department of Histopathology, E-Floor, Royal Hallamshire Hospital Sheffield S10 2JF (UK)

E-Mail hardeep.mudhar@sth.nhs.uk 
Fig. 1. a Clinical photograph showing the mass involving the right eyebrow with overhanging of the right upper eyelid. b Scanning power haematoxylin and eosin (HE)stained image of the lesion showing circumscription. c Higher-power HE-stained image showing the adipocytes (thin arrow) and the classical rope-like collagen fibres (thick arrow). d HE staining showing the hyperchromatic multi-nucleate floret cells (the best example is the cell in the middle showing the circle of nuclei). e Immunohistochemistry for CD34 showing the positive brown staining of the multi-nucleate floret cells and some background spindle cells.
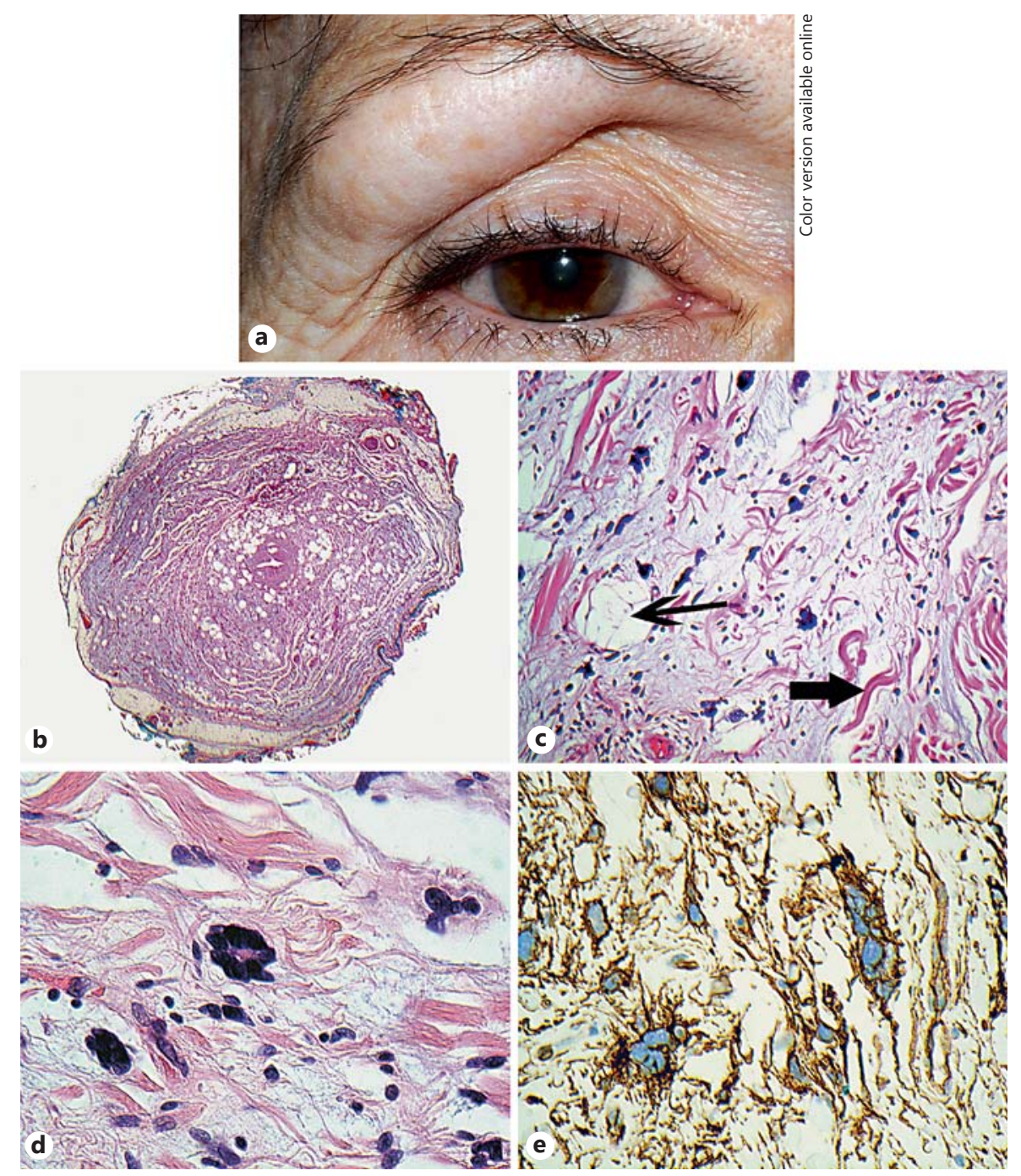

in the right brow soft tissue (fig. 1a). The clinical differential diagnosis included a cyst, neurofibroma, schwannoma, prolapsed orbital fat and a metastatic malignancy. Under general anaesthetic cover, an incision on the upper border of the right brow was made, and an encapsulated, well-defined sausage-shaped, yellowish-white lesion was identified. The lesion was dissected neatly and was fixed in standard buffered formalin for histopathological examination.

\section{Results}

Macroscopically, the lesion was a smooth, yellow to white ellipsoid, $23 \times 10 \times 8 \mathrm{~mm}$ in size, with a greyish, myxoid cut surface, focally surrounded by a rim of subcuticular adipose tissue. Histology showed a collagen-encapsulated lesion with a myxoid stroma containing adi- pocytes, some mast cells, collagen and multi-nucleate cells. The adipocytes showed focal variation in size compared to the background subcutis adipose tissue, but there were no atypical adipocyte nuclei and no lipoblasts. The collagen was rope-like. There were numerous multinucleate, hyperchromatic cells with a floret-like appearance. Some stubby spindle cells were seen accompanying the multi-nucleate cells. There was no mitotic activity, and no malignancy was identified. Immunohistochemical analysis showed that the multi-nucleate cells and the spindle cells were strongly positive for CD34 and negative for S100, desmin and smooth muscle actin. S100 stained the adipocytes only. The histological and immunohistochemical features were those of a classical pleomorphic lipoma. The patient has been followed up for almost 12 months without recurrence. 


\section{Discussion and Conclusions}

Primary tumours that affect the eyebrow can be considered at the level of the skin and subcutis. The commonest primary tumours are a variety of benign and malignant adnexa-derived epithelial tumours, of which the commonest is benign pilomatrixoma [1] that primarily affects the paediatric age group and presents as a chalky white nodule. A variety of eyebrow soft tissue lesions have been documented in case reports/series; they include fibrous histiocytoma [3], osteoma cutis [4], cellular neurothekeoma [5], dermatofibrosarcoma protuberans [6], rhabdomyoma [7], neurofibroma [8], nodular fasciitis [9] and conventional lipoma [10].

This case report describes a primary pleomorphic lipoma in the eyebrow subcutis. The clinical differential diagnosis included neurofibroma/schwannoma. This was based on the shape of the lesion (sausage-shaped, implying an association with a peripheral nerve). The other differential diagnoses included a cyst, prolapsed orbit fat and a metastasis. The classical cyst to affect the eyebrow area is the angular dermoid cyst [2]. This usually appears in childhood, although sometimes, a rupture of an occult angular dermoid can lead to an adult presentation with pain and inflammation. The lesion in question was not located at the angular aspect of the eyebrow and was painless and not associated with inflammatory type signs of the overlying skin. Prolapsed orbit fat usually presents as a bilateral yellowish mass under the supero-temporal conjunctiva and does not usually present as an eyebrow mass [11]. Given the age of the patient, the clinicians also entertained lymphoma and metastatic carcinoma, previously described at this site $[12,13]$.

Current classifications regard pleomorphic lipoma and spindle cell lipoma as one entity as many cases share a spectrum of appearances between the spindle variant and the purely pleomorphic variant and all cases share identical genetic changes of loss of material from chromosomes 16q and 13q [14]. Pleomorphic lipoma/spindle cell lipoma classically occurs in men on the posterior neck, shoulder and back, although other unusual sites have been documented (e.g. oral cavity). It is described as solitary, slow growing, well circumscribed and encapsulated, located in the subcutis and painless. All these features were present in our case [14]. The histological differential diagnosis of pleomorphic lipoma includes a variety of benign and malignant soft tissue entities. These include dermatofibrosarcoma protuberans, nodular fasciitis, angiomyofibroblastoma, solitary fibrous tumour, schwannoma and neurofibroma as well as well-differentiated liposarcoma [15]. The key features that distinguish pleomorphic lipoma from these entities are the presence of classic ropey collagen (not found in any of the other entities listed), the lack of thick-walled blood vessels (found in angiomyofibroblastoma), non-wavy spindle cells (wavy spindle cells are a feature of neurofibroma and schwannoma), lack of S100 positivity, strong and consistent CD34 positivity that also stains the multi-nucleate floret cells, circumscription and the lack of lipoblasts (lipoblasts are present in well-differentiated liposarcoma) [15]. A condition with which pleomorphic lipoma has been confused histologically is orbital fat prolapse as the latter shows hyperchromatic floret-type cells that are positive for CD34. However, fat prolapse does not contain a population of spindle cells, and rope-like collagen is absent [16]. Pleomorphic and spindle cell lipomas have been described in the eyelid (these cases were primary eyelid cases and some extended to involve the eyebrow) in a handful of case reports [10,17-21].

In summary, we have described the clinical, histological and immunohistochemical features of the first reported case of a primary pleomorphic lipoma of the eyebrow subcutis together with a detailed discussion of the clinical and histological differential diagnoses with which it can be confused. Awareness of this will allow an accurate and safe diagnosis to be made and will avoid an over-diagnosis of conditions such as well-differentiated liposarcoma.

\section{Statement of Ethics}

The patient gave consent to publish the photograph of the eye even though the cropped photo does not permit recognition. This consent is in the patient medical notes and can be made available on request. The study was conducted in accordance with the Declaration of Helsinki.

\section{Disclosure Statement}

The authors have no conflicts of interest to declare.
Hamilton/Tan/Mudhar 


\section{References}

$>1$ Yap EY, Hohberger GG, Bartley GB: Pilomatrixoma of the eyelids and eyebrows in children and adolescents. Ophthal Plast Reconstr Surg 1999;15:185-189.

$>2$ Brownstein MH, Helwig EB: Subcutaneous dermoid cysts. Arch Dermatol 1973;107:237239.

-3 Mentzel T, Kutzner H, Rutten A, Hugel H: Benign fibrous histiocytoma (dermatofibroma) of the face: clinicopathologic and immunohistochemical study of 34 cases associated with an aggressive clinical course. Am J Dermatopathol 2001;23:419-426.

$\checkmark 4$ Abessi B, Meyer DR, Carlson JA: Osteoma cutis (nevus of nanta) of the eyebrow. Ophthal Plast Reconstr Surg 2012;28:74-75.

$\checkmark 5$ Clark FL, Somoano B, Taube J, et al: Eyebrow papule in an elderly man. Dermatol Online J 2009;15:14.

6 Brazzo BG, Saffra N: Dermatofibrosarcoma protuberans of the brow and eyelid. Ophthal Plast Reconstr Surg 2004;20:332-334.
7 Konrad EA, Hubner G: Rhabdomyoma of the eyebrow region: a light and electron microscopic study of a recurrent rhabdomyoma of fetal type. Graefes Arch Clin Exp Ophthalmol 1983;220:187-192.

8 Mortada A: Neurofibromatosis of lid and orbit in early childhood. J Pediatr Ophthalmol 1977;14:148-150.

$\checkmark 9$ Font RL, Zimmerman LE: Nodular fasciitis of the eye and adnexa. A report of ten cases. Arch Ophthalmol 1966;75:475-481.

10 Hornblass A, Herschorn BJ: Carbon dioxide laser surgery on hemophilia. Am J Ophthalmol 1983;96:689-690.

11 Jordan DR, Tse DT: Herniated orbital fat. Can J Ophthalmol 1987;22:173-177.

12 Mosely LH, Fischer DS, Polayes IM: Asymptomatic eyebrow mass: a rare presenting sign of malignant non-Hodgkin's lymphoma. Arch Surg 1978;113:303-305.

13 Peris K, Cerroni L, D’Alessandro I, Chimenti $\mathrm{S}$ : Cutaneous eyebrow metastasis in a patient with primary gastric adenocarcinoma. Acta Derm Venereol 1994;74:154-155.

14 Fletcher CDM, Bridge JA, Hogendoorn PCW, Mertens F: WHO Classification of Tumours of Soft Tissue and Bone, ed 4. Lyon, WHO Press, 2013, pp 29-30.
15 Goldblum JR, Folpe AL, Weiss SW: Enzinger and Weiss's Soft Tissue Tumors, ed 6. Philadelphia, Elsevier Saunders, 2014, pp 456-463.

16 Schmack I, Patel RM, Folpe AL, et al: Subconjunctival herniated orbital fat: a benign adipocytic lesion that may mimic pleomorphic lipoma and atypical lipomatous tumours. Am J Surg Pathol 2007;31:193-198.

17 Thyparampil P, Diwan AH, Diaz-Marchan P, et al: Eyelid lipomas: a case report and review of the literature. Orbit 2012;31:319-320.

18 Buller A, O’Donnell A, Bonshek RE, Leatherbarrow B: Intramuscular lipoma of the eyelid: a case report. Eye 2004;18:743-745.

19 Charles NC, Palu RN: Intramuscular lipoma of the eyelid. Ophthalmic Surg Lasers 2000; 31:340-341.

20 Mawn LA, Jordan DR, Olberg B: Spindle-cell lipoma of the preseptal eyelid. Ophthal Plast Reconstr Surg 1998;14:174-177.

21 Sharara N, Lee WR, Weir C: Myolipoma of the eyelid. Graefes Arch Clin Exp Ophthalmol 1998;236:630-634. 